\title{
Tactile Cartography Courses in the Continued Education of Teachers from Latin America
}

\author{
Waldirene Ribeiro do Carmo ${ }^{\mathrm{a}, *}$, Carla Cristina Reinaldo Gimenes de Sena ${ }^{\mathrm{b}}$, \\ ${ }^{a}$ USP, Waldirene Ribeiro do Carmo - walcarmo@usp.br \\ ${ }^{b}$ UNESP, Carla Cristina Reinaldo Gimenes de Sena - carla.sena@unesp.br \\ * Corresponding author
}

Keywords: Teacher training, Tactile Cartography, Courses in Latin America

\begin{abstract}
:
One of the objectives of the International Cartographic Association (ICA) is facilitating the transfer of new cartographic knowledge inside and among nations, especially in developing countries, by providing specialists to lead workshops and courses when requested. In this sense, the Commission on Maps and Graphics for Blind and Partially Sighted People offers diverse courses in partnership with researchers from the Centro de Cartografia Tátil (Tactile Cartographic Center) at Universidad Tecnológica Metropolitana de Santiago de Chile. The faculty is multidisciplinary, formed by cartographers, geographers, special education teachers, designers, among others.
\end{abstract}

Approaching theoretical questions related to the Introduction to Cartography and Tactile Cartography, and also the development of practical activities, such as the construction of tactile instructional materials (in collage and aluminum) which prioritize the use of low-cost materials to assure they are affordable to all groups, but also demonstrating alternatives based on digital technologies like 3D printers and the use dynamics of these materials in schools. The main goal of the courses is to demonstrate construction techniques of tactile graphic representations inside an inclusive educational policy, as well as to make participants aware of the importance of tactile graphic representations for the teaching/learning of geography and other areas in an interdisciplinary perspective. In general, they are presented to heterogeneous groups (teachers of students with special educational needs, teachers of "regular" groups (of geography and other subjects), cartographers, etc.).

The courses, which are one-week long, started to be presented in Santiago de Chile in 2003, and there were other editions in 2004, 2005, 2006, 2007, 2009, 2012, 2013 and 2018, and they always had participants from several countries from Latin America (Argentina, Bolivia, Brazil, Colombia, Costa Rica, Chile, Ecuador, El Salvador, Guatemala, Honduras, Mexico, Nicaragua, Panama, Paraguay, Peru, Dominican Republic, Uruguay, and Venezuela), and later the team was invited to run the courses in Argentina (2004), Mexico (2004), Costa Rica (2016), Ecuador and Dominican Republic (2019).

The experience with the courses demonstrated the importance of continuing education for teachers in the different education stages and for professionals who assist people with special needs, and the possibility of exchanging experiences, highlighting the inclusion of disabled students in the regular classroom. Primarily in what concerns geography teachers, it was noticed that there is little or no knowledge about the specificities of visually impaired students and their needs in relation to geography teaching and the use of graphic representations.

On the other hand, teachers who had specific education to teach students with special educational needs and are located in multifunctional resources' rooms or some of the remaining special needs' schools lack specific knowledge about geography and cartography. These teachers need to assist the demands of all subjects and, many times, despite their efforts, they end up making inappropriate adaptations of materials, because they ignore the principles which must be observed in the transposition of visual/digital/printed materials into the tactile format.

The organizing team developed a basic structure of themes that are approached to meet the participants' expectations, and the themes are organized in the modules: Geo-cartographic concepts, techniques for preparation and reproduction of maps and relief illustrations, application of maps and tactile instructional materials to education. 
With a figure of about 300 participants, it was noticed how the practices stimulate the teachers' creativity and encourage them to create activities and group exercises for the classroom. Besides, the courses provide the reflection on how cartography can help geography teaching when it is done in a way that is more dynamic and meaningful for the students.

\section{Acknowledgements}

Pan American Institute of Geography and History 